\title{
Literature Review of Relative Poverty Research
}

\author{
Xiaomei Pu \\ Sichuan University of Arts and Science, Dazhou, China \\ Email: 47872614@qq.com
}

How to cite this paper: $\mathrm{Pu}, \mathrm{X}$. M. (2020). Literature Review of Relative Poverty Research. Voice of the Publisher, 6, 84-90. https://doi.org/10.4236/vp.2020.63008

Received: August 22, 2020

Accepted: September 11, 2020

Published: September 14, 2020

Copyright (c) 2020 by author(s) and Scientific Research Publishing Inc. This work is licensed under the Creative Commons Attribution International License (CC BY 4.0).

http://creativecommons.org/licenses/by/4.0/

\begin{abstract}
Relative poverty is a common social phenomenon. The elimination of relative poverty can stimulate social vitality, and create the development of the whole society with high quality. This study systematically organizes the relative poverty research from three aspects: connotation, identification method, and resolution mechanism, in order to lay a foundation for the relative poverty governance and the long-term resolution mechanism of relative poverty in China.
\end{abstract}

\section{Keywords}

Relative Poverty, Connotation, Identification Method, Resolution Mechanism

\section{Introduction}

In 2020, China will achieve targeted poverty alleviation, and absolute poverty will be solved. But relative poverty will still exist for a long time. Therefore, in 2019, the Central Committee of the Communist Party of China announced in the Fourth Plenary Session of the 19th Central Committee of the Communist Party of China: "it is necessary to take all the efforts to win the battle of poverty alleviation, consolidate the achievements of it, and establish a long-term mechanism to solve this problem." This is not only the fundamental requirement of the Central Committee of the CPC for consolidating the achievements of targeted poverty alleviation and preventing any relapse into poverty, but also the fundamental requirement of how to tackle relative poverty after targeted poverty alleviation. To establish the long-term mechanism for solving relative poverty, it is particularly important to understand the connotation and identification method of relative poverty. Therefore, this study will summarize the relative poverty research from three aspects: relative poverty connotation, identification me- 
thod, and resolution mechanism.

\section{Connotation of Relative Poverty}

\subsection{Foreign Research}

In the early stage, foreign scholars only understood relative poverty from the perspective of economic phenomenon, and defined relative poverty with relative income as the breakthrough point. Until 1979, Peter Townsend (1979) proposed the theory of relative poverty in his classic study Poverty in the United Kingdom: A Survey of Household Resources and Standards of Living. This theory defines relative poverty on the basis of "Relative Deprivation". It refers to the absence or inadequacy of those diets, amenities, standards, services and activities which are common or customary in society, which enriches the connotation of relative poverty and broadens the research vision of relative poverty. After that, Amartya Sen (1981) acknowledged Relative Deprivation by Peter Townsend in his book Poverty and Famines: An Essay on Entitlement, and proposed that poverty is, of course, a matter of deprivation. In order to solve the problem of establishing the poverty theory with thorough relativity, Amartya Sen introduced the concept of "Capacity Poverty" for the first time. On the basis of capacity poverty theory, foreign scholars have transferred their research on poverty to the multi-dimensional perspectives of vulnerability, discourse power, and social exclusion. One of the representatives is Robert Chambers. He conducted a groundbreaking study on the helplessness and isolation of the poor, which believed that poverty refers to lack of physical necessities, assets, and income, but is more than being income-poor (Chambers, 1995). The understanding of foreign scholars on the connotation of relative poverty has experienced a continuous deepening process from single dimensional to multi-dimension, providing a certain foundation for the governance of relative poverty in China.

\subsection{Research in China}

Since the 1990s, with the promotion of anti-poverty practices around the world and the widening income gaps in China, domestic scholars have continuously made the further study on relative poverty. The early definition of relative poverty was mainly limited to economic income and reproduction capacity. For example, Tong Xing and Lin Mingang (1994) believed that relative poverty was basically solved food and clothing, simple reproduction can be maintained, but it is lower than the basic living standard recognized by the society and lacks. The ability or ability to expand reproduction is very weak. Qin Jianjun and Rong Aiping (2012) believed that relative poverty refers to the living conditions of a person or family whose income is lower than the social average level to a certain extent. Liu Zongfei, Yao Shunbo, and Qu Mei (2013) believed that relative poverty refers to the social living conditions maintained when the income level is lower than the social average level to a certain extent, and the income difference between and within each social class. With the implementation and gradual 
completion of targeted poverty alleviation, the understanding of relative poverty has gradually deepened. Xing Chengju and Li Xiaoyun (2019) believed that relative poverty in the new era refers to the legal income obtained by an individual or family which can maintain the basic survival needs of family members, but cannot meet other basic living needs of local conditions, under the specific local production, living conditions, and the specific economic and social development constraints.

In general, researches at home and abroad have conducted in-depth discussions on the connotation of relative poverty from the aspects of income levels, deprivation of rights, and reproduction capabilities, which build some foundations for solving the relative poverty in China. However, since relative poverty of China will face new situations and characteristics after 2020, we must give a new definition of relative poverty in the new era. Relative poverty is a dynamically changing concept, and its core is relative and multidimensional. According to the new development situation of China after 2020, considering the new basic needs of people, we believe that the relative poverty refers to the living conditions in which the income, education, health, pension, and other security obtained by individuals or families, and the production and living environment are lower than the social average level to a certain extent.

\section{Identification Method of Relative Poverty}

The determination of the relative poverty standard is not only a hot issue, but also an important basis for establishing a long-term mechanism for relative poverty governance. Currently, there are several methods to identify relative poverty.

\subsection{Income Method}

The income method takes a certain proportion of social income as the relative poverty line, but there is no unified standard for the selection of its base and the determination of its proportion. The main countries that use income method to determine relative poverty are Britain, Japan, Singapore, and so on. Britain takes $60 \%$ of the national median household income as the relative poverty line; Japan was $50 \%$ of the middle-income household income; Singapore defines the lowest $20 \%$ of the household income; and the EU member countries take $50 \%$ or $60 \%$ of the median household income. While, the standard of relative poverty line proposed by the International Organization for Economic Cooperation and Development (OECD) is $50 \%-60 \%$ of the middle-income or social median income of a country or region. Domestic scholars have also carried out some research on the determination of the relative poverty line. Some scholars like Xing Chengju, Li Xiaoyun, Xi Xuehong, Sun Jiuwen, and Xia Tian believe that the standard of relative poverty line should be determined by a certain proportion of the median income of permanent residents or urban residents after 2020. Xing Chengju and Li Xiaoyun (2019) believe that it is appropriate to set this ratio at 40\%. While, Xi 
Xuehong (2012) and others think that it should be set as 50\%. However, Sun Jiuwen and Xia Tian (2019) think that this proportion should be adjusted by a certain period of time as the adjustment cycle (such as 5 years, or 10 years). On the other hand, Chen Zongsheng and Zhang Qing proposed that the per capita net income should be taken as the base selection standard. Based on this standard, Chen Zongsheng et al. (2013) suggested the proportion of $40 \%-50 \%$ was appropriate, but Zhang Qing (2012) thought that the ratio should be set at one third to $40 \%$. Nevertheless, Yang Yang and Ma Xiao (2012) proposed that the standard of relative poverty line should be set by total assets rather than income expenditure. Conversely, Chi Zhenhe and Yang Yiyong (2013) suggested that the standard of relative poverty line should be set based on per capita consumption.

Generally, this method is simple and easy to operate. However, with the development of social economy, this method of measuring relative poverty from single aspect can neither fully reflect the needs of civilians, nor embody the people-oriented development concept of China.

\subsection{Standard Budget Method}

Standard budget method, also known as market basket method, can be used to determine absolute poverty line and relative poverty line. It requires a list of daily necessities first, and then the amount of cash needed to own these necessities according to the market price is the poverty line. When the poverty line is set by experts, it is the absolute poverty line; when it is determined by the poverty representative, it is the relative poverty line. This method was proposed by RownTree in the study of Yorkshire poverty, and has been developed into several methods, such as the acceptable minimum cost of living method, the minimum healthy living income method, and the acceptable budget standard method (Deeming, 2005).

This method has a certain degree of transparency, acceptable, and understandable. However, the establishment of budget standards is relatively difficult, because the necessities are difficult to select and determine, and the prices vary greatly in different regions and at different times.

\subsection{Extended Linear Expenditure System}

The extended linear expenditure system is a poverty line measurement method based on the linear expenditure system, which was proposed by the British economist Liuch. This method is similar to the budget standard method in drawing up the relative poverty line. It takes the expenditure of consumer on various goods or services as a function of income and price, and calculates the relative poverty line on the necessities selected by residents themselves. It differs from the budget standard method in that it does not determine the list of necessities through the discussion of representatives, but calculates the relative poverty line through household consumption data.

This method effectively solves the problem of different prices in different re- 
gions at different times. Meanwhile, the collected data are relatively less affected by human factors, and the calculation method is more scientific. However, the statistics may not be able to calculate the family income items such as house rent and in-kind income, resulting in underestimation of income and certain deviations in the results.

\subsection{Social Index Method}

The social index method is a method to calculate the relative poverty line by calculating the deprivation degree of group members, that is, the degree to which the resources of group members are lower than the amount of resources recognized by the group. The social index method believes that the deprivation of group members is multifaceted, so it is necessary to select different indicators to reflect the degree of deprivation of group members, and the deprivation indicators must have the characteristics of popularity, additivity, effectiveness, and credibility. After setting the deprivation index, we can calculate the gap between the group members and the amount of daily necessities recognized by their groups, that is, the degree of deprivation. Therefore, after calculating the degree of deprivation of all group members, the relative poverty line can be calculated according to the relationship between income and the degree of deprivation (Chi \& Yang, 2012).

This method determines the index system based on the survey of the whole society rather than just the poor groups, which makes the calculation results more reasonable. However, due to the fact that the deprivation of production, living environment and other factors has little relationship with the income of individuals or families, so it is unreasonable to link all deprivations with income.

\subsection{Multidimensional Poverty Measurement}

According to multidimensional poverty theory, poverty includes not only income poverty, but also the deprivation of rights such as services, social welfare, and security. In order to measure the poverty level of individuals or families correctly, it is necessary to measure the degree of deprivation from multiple dimensions at the same time, and set up several indicators under each dimension, with corresponding deprivation threshold and weight for each index. If the deprivation thresholds of these indicators are set to a certain fixed value, then they are calculated as the multi-dimensional absolute poverty; if they are set based on the relative social level, then they are calculated as multi-dimensional relative poverty. At present, the most representative multidimensional poverty measurement system is the Global Multidimensional Poverty Index (Global MPI) published by the United Nations Development Program (UNDP) and the Poverty and Human Development Research Center of Oxford University. This system includes three dimensions: health, education, and living standards. Mexico, Colombia and other countries have also developed their own multidimensional poverty index and standard, but there are no official unified ones in China. 
This method breaks the traditional poverty measurement which is limited by the currency dimension, and can better measure the depth and breadth of relative poor population.

\section{Resolution Mechanism of Relative Poverty}

With the gradual completion of targeted poverty alleviation and the proposal of establishing a long-term mechanism to solve relative poverty, Chinese scholars put forward a long-term mechanism for solving relative poverty after 2020 from the aspects of key difficulties and main contents. Fan Hesheng and Wu Zhengyu (2020) thought that the long-term mechanism for solving relative poverty should be explored from five major and difficult points, such as system guarantee, industrial cultivation, capacity-building, humanistic development, and psychological service. Jiang Yongmu (2020) believed that long-term mechanism to solve relative poverty should from identification mechanism, security mechanism, and dynamic mechanism. Lv Fang (2020) believed that we should establish a long-term mechanism to solve relative poverty in terms of policy response, economic growth tolerance, and social participation. The above research provides a certain reference for the establishment of a long-term mechanism to solve relative poverty in China. Due to the different causes, manifestations, and governance paths of relative poverty in different regions and stages, it is necessary to study each typical region. However, there is little research on the long-term mechanism of solving relative poverty in typical regions.

\section{Conclusion}

This study summarizes the relative poverty research from three aspects: connotation, identification method, and solution mechanism, which provides the basis for the governance of relative poverty and the establishment of long-term mechanism for solving relative poverty in China. However, relative poverty is a dynamic, multi-dimensional, and regional problem. It is necessary to conduct multi-dimensional measurement for each typical region in China in the new era, and put forward corresponding long-term mechanism.

\section{Funding}

This study is funded by the Development and Research Center of Sichuan Old Revolutionary Base Areas, which is named Research on Targeted Poverty Alleviation in Sichuan Old Revolutionary Base Areas from the Perspective of Income Sources (SLQ2018C-14).

\section{Conflicts of Interest}

The author declares no conflicts of interest regarding the publication of this paper.

\section{References}

Chambers, R. (1995). Poverty and Livelihoods: Whose Reality Counts? Environment and 
Urbanization, 7, 173-204. https://doi.org/10.1177/095624789500700106

Chen, Z. S., Shen, Y. Y., \& Zhou, Y. B. (2013). The Absolute and Relative Changes of Rural Poverty in China-On the Setting of Relative Poverty Line. Management World, 1, 67-77.

Chi, Z. H., \& Yang, Y. Y. (2012). Review of Poverty Line Research. Economic Theory and Business Management, 7, 56-64.

Chi, Z. H., \& Yang, Y. Y. (2013). Study on the Scale and Change Trend of Urban Low Income Groups Based on the Data of Urban Household Survey in Beijing. Population \& Economics, 2, 100-107.

Deeming, C. (2005). Minimum Income Standards: How Might Budget Standards Be Set for the UK? Journal of Social Policy, 34, 619-636. https://doi.org/10.1017/S0047279405009189

Fan, H. S., \& Wu, Z. Y. (2020). Research on the Construction of Long-Term Effective Mechanism of Relative Poverty Control. Studies on the Socialism with Chinese Characteristics, 1, 63-69.

Jiang, Y. M. (2020). Establishing a Long-Term Mechanism of Solving Relative Poverty. China Review of Political Economy, 3, 28-34.

Liu, Z. F., Yao, S. B., \& Qu, M. (2013). The Dynamic Evolution of the Relative Poverty of Rural Households in Wuqi: 1998-2011. China's Population: Resources and Environment, 3, 56-62.

Lv, F. (2020). Poverty Reduction and Governance after 2020: Establishing a Long-Term Mechanism to Solve the Problem of Relative Poverty. Expanding Horizons, 2, 33-39.

Qin, J. J., \& Rong, A. P. (2012). Analysis of the Impact of Financial Expenditure Structure on Relative Poverty in Rural Areas. Economic Issues, 11, 95-98.

Sen, A. (1981). Poverty and Famines: An Essay on Entitlement and Deprivation. Oxford: Clarendon Press.

Sun, J. W., \& Xia, T. (2019). China's Poverty Alleviation Strategy and the Delineation of the Relative Poverty Line after 2020: An Analysis Based on Theories, Policies and Data. Chinese Rural Economy, 10, 98-113.

Tong, X., \& Lin, M. G. (1994). Research on Rural Poverty Standard Line in China. Social Sciences in China, 3, 86-98.

Townsend, P. (1979). Poverty in the United Kingdom: A Survey of Household Resources and Standards of Living. Harmondsworth: Penguin Books Ltd.

Xi, X. H. (2012). An Empirical Study on the Dynamic Evolution of Relative Poverty of Rural Residents in Henan Province. Anhui Agricultural Sciences, 18, 9933-9935.

Xing, C. J., \& Li, X. Y. (2019). Relative Poverty and the Construction of Poverty Governance Mechanism in the New Era. Reform, 12, 16-24.

Yang, Y., \& Ma, X. (2012). An Empirical Study of Floating Population and Relative Poverty in Cities. Guizhou Social Sciences, 10, 125-128.

Zhang, Q. (2012). Relative Poverty Standard and Relative Poverty Population Ratio. Statistics and Decision, 6, 87-88. 